Computer Science \& Information Technology 

Dhinaharan Nagamalai

Natarajan Meghanathan (Eds)

\section{Computer Science \& Information Technology}

$3^{\text {rd }}$ International Conference on Natural Language Processing (NATP 2017) December 30 31, 2017, Dubai, UAE 


\section{Volume Editors}

Dhinaharan Nagamalai,

Wireilla Net Solutions, Australia

E-mail: dhinthia@yahoo.com

Natarajan Meghanathan,

Jackson State University, USA

E-mail: nmeghanathan@jsums.edu

ISSN: $2231-5403$

ISBN: 978-1-921987-77-9

DOI : $10.5121 /$ csit.2017.71701 - 10.5121/csit.2017.71703

This work is subject to copyright. All rights are reserved, whether whole or part of the material is concerned, specifically the rights of translation, reprinting, re-use of illustrations, recitation, broadcasting, reproduction on microfilms or in any other way, and storage in data banks. Duplication of this publication or parts thereof is permitted only under the provisions of the International Copyright Law and permission for use must always be obtained from Academy \& Industry Research Collaboration Center. Violations are liable to prosecution under the International Copyright Law.

Typesetting: Camera-ready by author, data conversion by $\mathrm{NnN}$ Net Solutions Private Ltd., Chennai, India 


\section{Preface}

The $3^{\text {rd }}$ International Conference on Natural Language Processing (NATP 2017) was held in Dubai, UAE, during December 30 31, 2017. The $3^{\text {rd }}$ International Conference on Software Engineering (SOFE-2017) was collocated with The $3^{\text {rd }}$ International Conference on Natural Language Processing (NATP 2017). The conferences attracted many local and international delegates, presenting a balanced mixture of intellect from the East and from the West.

The goal of this conference series is to bring together researchers and practitioners from academia and industry to focus on understanding computer science and information technology and to establish new collaborations in these areas. Authors are invited to contribute to the conference by submitting articles that illustrate research results, projects, survey work and industrial experiences describing significant advances in all areas of computer science and information technology.

The NATP-2017, SOFE-2017 Committees rigorously invited submissions for many months from researchers, scientists, engineers, students and practitioners related to the relevant themes and tracks of the workshop. This effort guaranteed submissions from an unparalleled number of internationally recognized top-level researchers. All the submissions underwent a strenuous peer review process which comprised expert reviewers. These reviewers were selected from a talented pool of Technical Committee members and external reviewers on the basis of their expertise. The papers were then reviewed based on their contributions, technical content, originality and clarity. The entire process, which includes the submission, review and acceptance processes, was done electronically. All these efforts undertaken by the Organizing and Technical Committees led to an exciting, rich and a high quality technical conference program, which featured high-impact presentations for all attendees to enjoy, appreciate and expand their expertise in the latest developments in computer network and communications research.

In closing, NATP-2017, SOFE-2017 brought together researchers, scientists, engineers, students and practitioners to exchange and share their experiences, new ideas and research results in all aspects of the main workshop themes and tracks, and to discuss the practical challenges encountered and the solutions adopted. The book is organized as a collection of papers from the NATP-2017, SOFE-2017.

We would like to thank the General and Program Chairs, organization staff, the members of the Technical Program Committees and external reviewers for their excellent and tireless work. We sincerely wish that all attendees benefited scientifically from the conference and wish them every success in their research. It is the humble wish of the conference organizers that the professional dialogue among the researchers, scientists, engineers, students and educators continues beyond the event and that the friendships and collaborations forged will linger and prosper for many years to come.

Dhinaharan Nagamalai

Natarajan Meghanathan 


\section{Organization}

\section{General Chair}

David C. Wyld

Jan Zizka

\section{Program Committee Members}

Southeastern Louisisna University, USA

Mendel University in Brno, Czech Republic

\author{
Abd El-Aziz Ahmed \\ Abdallah Rhattoy \\ Abdel-Aziz Ahmed \\ Abdelhamid Mansor \\ Abdellatif Berkat \\ Abdelmonaime Lachkar \\ Abdulkader Omar Alwer \\ Adam Przybylek \\ Ahmad A. Saifan \\ Ahmad Rafi Qawasmeh \\ Ahmed Sameh \\ Akrem Sellami \\ Ali Elkateeb \\ Ali Hussein Mohammed \\ Amin Karami \\ Amizah Malip \\ Ammar Almasr \\ Anandkumar Mani \\ Anas Shatnawi \\ Ankit Chaudhary \\ Arif Sari \\ Ashok Kumar \\ Ayad salhieh \\ Baghdad ATMANI \\ Barkat Warda \\ Bing Li \\ Chiranjib Sur \\ Cini Kurian \\ Dayang Norhayati Abang Jawawi \\ Deepak Laxmi Narasimha \\ Dongchen Li \\ Farzad Kiani \\ Filiz Cele Dr \\ Gurkana \\ Gurudas Nayak C \\ Haipeng Cai \\ Hamid Ali Abed AL-Asadi
}

Cairo University, Egypt

Moulay Ismail University, Morocco

Anna University, India

University of Khartoum, Sudan

Abou-Bekr Belkadd University, Algeria

SMBA University Fez, Morocco

Istanbul Aydin University, Turkey.

Gdansk University of Technology, Poland

Yarmouk University, Jordan

The Hashemite University,Jordan

Prince Sultan University, Kingdom of Saudi Arabia

IMT Atlantique, France

University of Michigan-Dearborn, USA

Alexandria University, Egypt

University of East London, UK

University of Malaya, Malaysia

Albalqa applied university, Jordan

Anna University, India

University of Quebec at Montreal, Canada

Truman State University, USA

European University of Lefke, Cyprus

University of Louisiana at Lafayette, USA.

Australian College, Kuwait

University of Oran, Algeria

University of Constantine 1, Algeria

Xi'An Technological University, China

University of Florida, US

Cochin University of Science \& Technology, India

Universiti Teknologi Malaysia (UTM), Malaysia

University of Malaya

Peking University, China

Istanbul S.Zaim University, Turkey

Istanbul Ayd UNniversity, Turkey

Yildiz Technical University, Turkey

Manipal University, India

Washington State University, USA

Basra University, Basra, Iraq 
HlaingHtakeKhaung Tin

Hossein Jadidoleslamy

Ilham Huseyinov

Isa Maleki

Iyad Alazzam

Janes Andrea

Jichiang Tsai

Jun Liu

Kevin Gary

Kheireddine Abainia

Lee Beng Yong

Mahdi Khemakhem

MarÃ-a J. Escalona

Mark Robert Anderson

Márta Takács

Marzak Bouchra

Meng Su

Miroslav Voznak

Miroslaw Kwiatkowski

Mohamed AMROUNE

Mohammad Reza

Mohammed A. Akour

Nahlah M. Ameen Shatnawi

Naren J

NASEEM I IBRAHIM

Nayer Fatima Mohammed

Nizar Chatti

Osama Rababah

Prakash Kotecha

Prantosh kumar Paul

Prasan Kumar Sahoo

Ramayah A/L Thurasamy

Ramgopal Kashyap

Saber Elsayed

Samer Zain

Sathyashankara Sharma

Selahattin KOSUNALP

Shadi R Masadeh

Shah J Miah

Soumaya Chaffar

Stefano Michieletto

Tanmoy Sarkar

Tanzila Saba

Tomasz Neumann

Tzung-Pei Hong

Yingxu Wang
University of Computer Studies, Myanmar

MUT University, Iran

Istanbul Aydin University, Turkey

Islamic Azad University, Iran

Yarmouk University, Jordan

Free University of Bozen-Bolzano, Italy

National Chung Hsing University, Taiwan

University of Michigan Dearborn, USA

Arizona State University, USA

USTHB university, Algeria

Universiti Teknologi MARA, Malaysia

Prince Sattam Bin Abdulaziz University, Saudi Arabia

University of Seville, Spain

Edge Hill University, UK

University of Novi Sad, Serbia

Hassan II University, Morocco

Penn State Erie, Behrend

VSB-Technical University of Ostrava, Czech Republic

AGH University of Science and Technology, Poland

Larbi Tebessi university, Algeria

Nami Qazvin Islamic Azad University, Iran

Yarmouk University, Jordan

Yarmouk University, Jordan

SASTRA University, India

Penn State University, USA

Prince Sultan University, Saudi Arabia

University of ANGERS, France

The University of Jordan, Jordan

Indian Institute of Technology, India

Raiganj University, India

Chang Gung University, Taiwan

Universiti Sains Malaysia, Malaysia

Sagar Institute of Science and Technology, India

University of New South Wales, Australia

Birzeit University, United Kingdom

Manipal University, India

University of Bayburt, Turkey

Isra University, Jordan

Victoria University, Australia

Prince Sultan University, Saudi Arabia

University of Padova, Italy

Microsoft Corporation, USA

Prince Sultan University, Saudi Arabia

Gdynia Maritime University, Poland

National University of Kaohsiung, Taiwan

University of Calgary, Canada 


\section{Technically Sponsored by}

Computer Science \& Information Technology Community (CSITC)

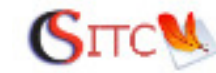

Networks \& Communications Community (NCC)

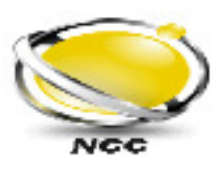

Digital Signal \& Image Processing Community (DSIPC)

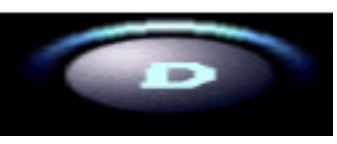

\section{Organized By}

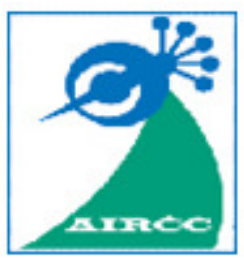

Academy \& Industry Research Collaboration Center (AIRCC) 


\section{TABLE OF CONTENTS}

\section{$3^{\text {rd }}$ International Conference on Natural Language Processing (NATP 2017)}

Study on Documentry Translation for Dubbing. $01-07$

Yunsil Jo

Machine Translation Evaluation in SNS in Terms of User-Centered

Orientation $09-13$

Kim Euna

\section{3rd International Conference on Software Engineering (SOFE-2017)}

Architecture and Technical Debt Agile Planning Methodology for Software

Production.

Aya Elgebeely and Amr Kamel 


\title{
STUDY ON DOCUMENTARY TRANSLATION FOR DUBBING
}

\author{
Yunsil Jo \\ Department of English Literature and Language, \\ Pusan National University, Busan, South Korea
}

\begin{abstract}
This paper discusses the features of documentary translation for dubbing and translation strategies for this kind of audiovisual genre. Especially it aims to analyze differences in the use of pronouns between source text and target text by making use of parallel corpus of English documentary scripts and their Korean translated versions. It is argued that these differences and translation strategies might be attributed to the viewers' expectancy described in Chesterman's norm theory.
\end{abstract}

\section{KEYWORDS}

Documentary translation, The Voice-over Translation of Documentaries, Audiovisual translation, Translation for dubbing, Chesterman's norm theory.

\section{INTRODUCTION}

The development of media has enabled us to enjoy various kinds of audiovisual products in our daily life. And as media supply channel has been diversified and viewers have started to voice their opinions and needs, diverse genres of programs are presenting on TV. Documentary is one of them. Documentary is well-known and popular genre but documentary translation has been relatively marginalized in translation study especially documentary translation for dubbing.

This paper focuses on how documentary translation for dubbing is different and what is the feature of this seemingly authentic genre. In addition it suggests strategies the translator can employ when working on this audiovisual product. These strategies are supported and explained with Chesterman's expectancy norms. And by using corpus methodology, pronoun translation patterns in the target text are analysed and explained.

This article is organized as follows. Section 2 gives theoretical framework with general feature of documentary genre and Chesterman's expectancy norms. Section 3 introduces data analysis including corpus analysis. And the conclusions are drawn in section 4. 
Computer Science \& Information Technology (CS \& IT)

\section{THEORETICAL FRAMEWORK}

\subsection{THE NATURE OF DOCUMENTARY}

Traditionally, documentaries are claimed to be based on reality and nonfiction program with image and narration. Now it is well known that this factual genre is not authentic reality but a result of the constructed reality with a perspective of the producer. The producer is the person who finds out meaning at the image and sound of the reality. And he selects and arranges the facts in accordance with his meaning. Narrations are an effective tool to deliver the producer's message.

Narration delivers theme of the episode in a persuasive way. So it has to be written consistently and coherently, reflecting producer's message. Narrations are delivered by a male narrator of a certain age. That's because people believe the voice of old man gives trust much stronger than their young or female counterparts. Narrators do not appear on the scene in the voice-over mode of documentary and narration is written with an omniscient viewpoint. Heard but not seen male voice with factual image gives viewers the illusion that they are seeing an authentic reality.

Unlike fiction work where shooting is based on script, documentary is produced by writing script based on the shooting image. That is, shooting first and writing next. After filming, the producer selects and arranges the image to put his meaning across persuasively. In this process narration is very salient tool to communicate with viewers. It has to be not too long and short and harmonious with image and coherent and consistent with the theme.

\subsection{CHESTERMAN'S EXPECTANCY NORM}

Chesterman's norm theory is described with two norms: expectancy norm and professional norm. Expectancy norm is about translation product norm. It says that this norm is made by expectancy of the readers in the target culture. Professional norm regulates translation process. This paper focuses on Chesternam's expectancy norm which is related to conventional rules in translating documentary. Readers or viewers in the target culture have expectancy that translation of this genre should be like that. This expectancy is partly controlled by pervasive translation tradition and similar genre in the target culture. It is sometimes affected by economical and ideological factors and power of authorities.

Readers or viewers in the target culture influence style, register, structure and selection of word when translating. When the translator behaves up to expectations their work is considered 'right' and 'good' one and this work could function as a convention to a future project. In this paper, the analysed documentary in the next section was broadcasted at $8 \mathrm{pm}$ on Sunday and viewers think the program is for all family members including children. So the narration should be rewrite to make easy to understand in the target culture.

\section{DATA ANALYSIS}

\subsection{THE COMPLIMENT OF DATA}

This paper is designed to compile and build corpus with documentary program. The corpus specifically includes scripts of four episodes of documentary which are episode 1, 2, and 3 of 
'WILD WEST' series by BBC and the second episode of 'Creative Killers' series by On Earth. These episodes are translated by the author and the author has got permission from the translation agency for the scientific use of the original scripts and translated versions. The documentary was broadcasted on Korean public television(KBS) at 8 pm on Sunday in March, 2017

\subsection{THE STRATEGIES FOR DOCUMENTARY TRANSLATION FOR DUBBING}

\subsubsection{ADD INFORMATION}

When unfamiliar terms such as names of animals and places, and geological phenomena appear in the narration of documentary, translators usually add annotation which is not in the original text. The table 1 shows translator's annotation. The annotation consists of definition or short explanation about the new information. And it will be shown at the left bottom corner of TV screen with the relative image at its first appearance or sometimes many times after that. In addition, viewers expect more detail information about new contents because many documentary programs have done that so far. So the translator behave on the expectancy of the target viewers. And considering the educational purpose for the children viewers, this kind of information delivery is much more effective than complete dependence on narrator's saying.

Table 1. Adding annotation

\begin{tabular}{|c|c|c|}
\hline ST & Translation & Annotation \\
\hline $\begin{array}{c}\text { It's now known as the Sea of } \\
\text { Cortez. (WILDWEST\#3 } \\
03: 27 \text { ) }\end{array}$ & $\begin{array}{c}\text { 오늘날 코르테즈 해라고 } \\
\text { 알려진 곳입니다. }\end{array}$ & $\begin{array}{c}\text { \#\# 코르테즈 해 :멕시코 } \\
\text { 북서부 태평양 연안의 } \\
\text { 해역, } \\
\text { 캘리포니아만이라고도 } \\
\text { 부름 }\end{array}$ \\
\hline $\begin{array}{l}\text { Vents and black-smokers, } \\
\text { some a hundred feet high, are } \\
\text { evidence of powerful tectonic } \\
\text { forces at work. } \\
\text { (WILDWEST\#3 06:13 ) }\end{array}$ & $\begin{array}{c}\text { 블랙스모커는 } 30 \text { 미터 높이 } \\
\text { 해저 굴뚝으로 / 지구 } \\
\text { 내부에 강력한 힘이 } \\
\text { 작용하고 있음을 보여주는 } \\
\text { 증거입니다. }\end{array}$ & $\begin{array}{c}\text { \#\# 블랙스모커(Black- } \\
\text { smoker) :해저의 지각 } \\
\text { 속에서 마그마가 식어 굳을 } \\
\text { 때 정출되는 수용액이 } \\
\text { 바닷물과 반응해 검은 } \\
\text { 연기처럼 솟아오르는 것 }\end{array}$ \\
\hline
\end{tabular}

\subsubsection{AVOID DIFFICULT EXPRESSIONS}

Like many other TV programs documentaries needs to be understood at once when broadcasting, but some episodes of this factual product contain a lot of difficult concepts and expressions in the original version which could lower the concentration and hinder the comprehension of the episode. And the translated version was shown at $8 \mathrm{pm}$ on Sundays so children are considered one of main viewers of this program in target culture. So translators choose terms and expressions that are easy to understand and help viewers focus only on the contents. The table 2 shows TT1 and TT2 have the same meaning, but TT1 use Chinese character noun and sound more difficult than pure Korean expression in TT2. That's why the producer finally select TT2 version. 
Table 2. Using easy expressions

\begin{tabular}{|c|c|c|}
\hline ST & TT1 & TT2 \\
\hline $\begin{array}{l}\text { Cutting its way through the } \\
\text { heart of the Wild West, } \\
\text { carrying rain and melt water } \\
\text { from the Rockies. } \\
\text { (WILDWEST \#1, 19:38) }\end{array}$ & $\begin{array}{l}\text { 강줄기는 서부의 중심부를 } \\
\text { 가로지르며/ 로키 산맥의 } \\
\text { 비와 융해수를 나릅니다. }\end{array}$ & $\begin{array}{c}\text { 와일드 웨스트 중앙을 } \\
\text { 가로지르며/ } \\
\text { 로키 산맥에 내린 비와 } \\
\text { 녹은 물을 쉼 없이 } \\
\text { 나릅니다./// }\end{array}$ \\
\hline
\end{tabular}

In the same vein in the table 3 the producer tend to prefer TT2 because the foreign word in TT1 can be replaced much easier Korean term.

Table 3. Avoiding foreign words

\begin{tabular}{|l|c|c|}
\hline \multicolumn{1}{|c|}{ ST } & \multicolumn{1}{|c|}{ TT1 } & TT2 \\
\hline $\begin{array}{l}\text { For a few weeks a year, } \\
\text { thanks to changing currents }\end{array}$ & 일 년에 몇 주간은/ 해류와 & 해류와 바람의 움직임이 \\
and wind patterns, heavy & 바람의 패턴이 변한 & 변하면서/ 태평양 상공의 \\
clouds roll in off the & 덕분에/ 태평양 상공에 & 먹구름이/ 시에라 네바다 \\
$\begin{array}{l}\text { Pacific past the Sierra } \\
\text { Nevada mountains and }\end{array}$ & 있는 먹구름이/시에라 & 산맥을 넘어/ 멀리 내륙의 \\
reach as far inland as & 네바다 산맥을 넘어/멀리 & 애리조나주 소노란 \\
$\begin{array}{l}\text { Arizona's Sonoran } \\
\text { desert.(WILDWEST \#1, }\end{array}$ & 내륙의 애리조나 소노라 & 사막까지 몰려옵니다./// \\
20:54) & 산맥에까지 몰려옵니다. & \\
& & \\
& & \\
\end{tabular}

\subsubsection{USE SIMPLE STRUCTURE}

Although original text is written in fancy and complex style, the translator should recreate the text in a simple and clear form and structure. This strategy can also be explained with Chesterman's expectancy norm. Viewers do not expect fine language in documentary. They want information and in that case simple and plain structure helps viewers follow the storyline and accept new information.

The table 4 shows two versions of translation and TT1 has longer subject and qualifier so when listening, people may not easily figure out what it is about. So it is recommended to keep subject short and avoid long qualifier with the subject. In addition, Korean word order is relatively flexible compared with English, but the basic form starting with subject is easy to understand. In the table 5 subject of TT1 is located in the middle of the sentence. When listening people feel more stable and comfortable when the subject is at the beginning of the clause like TT2. 
Table 4. Keeping subject short

\begin{tabular}{|c|c|c|}
\hline ST & TT1 & TT2 \\
\hline $\begin{array}{l}\text { Using nectar as a bribe, the } \\
\text { plants ensure many visits } \\
\text { from both female } \\
\text { hummingbirds and brightly } \\
\text { coloured males who } \\
\frac{\text { unwittingly collect pollen }}{\frac{\text { as they feed.(Wild West }}{\# 2,12: 04)}}\end{array}$ & $\begin{array}{l}\text { 그래서 꿀을 미끼로 이용해 } \\
\text { 암컷 안나벌새뿐 아니라,/ } \\
\text { 꿀을 먹는 동안 자기도 } \\
\text { 모르게 꽃가루를 모으는 } \\
\text { 밝은 색의 수컷도 많이 } \\
\text { 끌어들입니다./ }\end{array}$ & $\begin{array}{c}\text { 달콤한 꿀을 미끼로/ 암컷 } \\
\text { 안나벌새뿐 아니라,/ } \\
\text { 화려한 깃털을 가진 } \\
\text { 수컷까지 불러들여 / 꿀을 } \\
\text { 먹는 동안 꽃가루를 } \\
\text { 묻혀가게 유도합니다.// }\end{array}$ \\
\hline
\end{tabular}

Table 5. Locating subject at the beginning of the clause

\begin{tabular}{|c|c|c|}
\hline ST & TT1 & TT2 \\
\hline Yosemite falls plummet & 700미터보다 더아래로 & 요세미티 폭포는 700미터 \\
over 2,400 feet, the highest & 떨어지는 요세미티 & 까마득한 높이의/ \\
falls in North America. & 폭포는,/ 북아메리카에서 & 북아메리카에서 가장 \\
& 가장 높은 폭포입니다. & 항한 폭포죠.
\end{tabular}

\subsubsection{SPECIFY PRONOUN SUBJECT}

The pronoun subject in the source text tend to be specified in the target text. The table 6 shows how the pronoun in the original text is translated. The TT1 is using pronouns like English version but TT2 explicitate what 'it' is. And the producer consider TT2 more suitable because viewers may not be accustomed to 'Gila monster' and providing its full name once again could more helpful to viewers.

Table 6. Specifying pronouns

\begin{tabular}{|c|c|c|}
\hline ST & TT1 & TT2 \\
\hline $\begin{array}{l}\text { It's after the eggs of } \\
\text { ground nesting birds, } \\
\text { especially quail, a } \\
\text { delicacy! } \\
\text { Gila monsters can eat one } \\
\text { third of their body weight } \\
\text { in one hit. } \\
\text { (Wild West \#1, 12:15) }\end{array}$ & $\begin{array}{c}\text { 녀석은 메추라기와 같이 } \\
\text { 땅에 둥지를 트는 새의 } \\
\text { 알을 찾고 있습니다. } \\
\text { 별미거든요. } \\
\text { 한 번에 몸무게의 } 3 \text { 분의 } \\
1 \text { 에 해 당하는 양도 먹어 } \\
\text { 치웁니다. }\end{array}$ & $\begin{array}{c}\text { 힐러몬스터는 메추라기 } \\
\text { 같이 땅에 둥지를 트는 } \\
\text { 새의 알을 찾고 있습니다./ } \\
\text { 최고의 별미니까요.// } \\
\text { 힐러몬스터는 한 번에 자기 } \\
\text { 몸무게의 } 3 \text { 분의 } 1 \text { 에 } \\
\text { 달하는 양을 } \\
\text { 먹어치웁니다./// }\end{array}$ \\
\hline
\end{tabular}

\subsection{CORPUS ANALYSIS OF THE USE OF PRONOUNS}

In relation to the explicitation of the pronoun subject, this paper analyzes how pronouns are translated by making use of AntConC3.4.4.version. After compiling data the author compare and analyze translation patterns of pronouns. Pronouns including 'it', 'they', 'them', 'he', 'she', 'her', 
'him' are part of investigation and impersonal subject 'it' and introductory 'it' are excluded from the corpus.

Pronoun translations categorized four patterns: omission, explicitation, shift in structure or meaning and pronouns. The table 7 shows subject is missing in target language. Korean is highcontext language and subject and object are frequently omitted. Image explains many parts so subject and object sometimes feel like redundance. However, in some cases to meet the informative and educational purpose of this audiovisual product, pronouns in the source text are specified in translated version. The table 8 identifies 'them' and 'it' in the source text translated as '악어들이(crocodiles)' and '이 단층은(this fault).' The table 9 shows shift in structure or meaning. When the TT is backtranslated the clause including pronoun is like this: the deadlock is settled. The table 10 displays a pronoun '이들은' in the target text as in the source text.

Table 7. Omission

\begin{tabular}{|c|c|}
\hline ST & TT1 \\
\hline $\begin{array}{c}\text { They weigh nearly two hundred tonnes, and } \\
\text { can grow ninety feet long. (Wild West \#3, } \\
04: 08 \text { ) } \\
\text { And as it soaks up desert minerals it becomes } \\
\text { three times saltier than the sea...(Wild } \\
\text { West\#1, 41:54) }\end{array}$ & $\begin{array}{l}\text { 몸무게가 200톤에 육박하고,// } \\
27 \text { 미터까지 자랍니다./// } \\
\text { 또한, 사막의 무기질을 } \\
\text { 흡수했기 때문에 바닷물보다 염도가 세 } \\
\text { 배나 높습니다./ }\end{array}$ \\
\hline
\end{tabular}

Table 8. Explicitation

\begin{tabular}{|c|c|}
\hline ST & TT1 \\
\hline $\begin{array}{c}\text { Blood in the water attracts them like moths to } \\
\text { a flame. (Creative Killers\#2, 26:34) }\end{array}$ & 피 냄새를 맡고 악어들이 불나방처럼 \\
모여듭니다./// \\
$\begin{array}{c}\text { Ten miles deep and more than eight hundred } \\
\text { miles long, it highlights the boundary } \\
\text { between the world's biggest tectonic plates. } \\
\text { (Wild West \#3, 28:57) }\end{array}$ & $\begin{array}{c}\text { 깊이 16킬로미는어 이 단층은/ 지 질구조 판의 경계를 확연히 } \\
\text { 드러냅니다.// }\end{array}$ \\
\end{tabular}

Table 9. Shift in meaning or structure

\begin{tabular}{|c|c|}
\hline ST & TT1 \\
\hline $\begin{array}{c}\text { When the first few wildebeest drink, they } \\
\text { break the deadlock. (Creative Killers\#2, } \\
09: 10)\end{array}$ & 누군가 첫 발을 내딛으면/ 상황이 \\
& 해결됩니다./// \\
\hline
\end{tabular}


Table 10. Pronouns

\begin{tabular}{|c|c|}
\hline ST & TT1 \\
\hline $\begin{array}{c}\text { They have the ability to neutralise the toxic } \\
\text { water. Their fine hairs catch air bubbles, } \\
\text { allowing them to walk underwater to feed on } \\
\text { algae. (Wild West\#1,38:33) }\end{array}$ & 이들은 물의 독성을 중화시킬 수 \\
미세한 털로 기포를 잡고 물속에 들어 가 \\
조류를 먹습니다.//I
\end{tabular}

\section{CONCLUSions}

In this paper, the strategies for translating dubbed documentary are described and explained with the study of Chesterman's norms theory. Research shows the translator and producer tries to meet viewers' expectancy which is largely related to help them to easily understand the contents. As the air time of the documentary was evening time on the weekend, children were one of main viewers of the program. So the translator tries to use simple and easy terms and avoid difficult expressions and adopt basic structure when writing. In additions for the educational purpose of the genre and effective information delivery the translator specify pronouns of the source text in the target text. With the analysis of the corpus translated texts exhibit four patterns dealing with pronouns. It is argued that omission, explicitation, shift in meaning or structure and using pronouns are observed by analysing the corpus. Notwithstanding the size limitation of data there's difficulty in generalize strategies and aspects in translating documentary, this findings may help understand differences in translating documentary for dubbing. Similar studies can be conducted on documentary translation by using corpus methodology.

\section{REFERENCES}

[1] Andrew Chesterman, Natividad Gallardo San Salvador and Yves Gambier (ed.), (1998) "Translation in Context- Selected contributions from the east Congress", Canada. Philadelphia. Benjamins.

[2] BillNichols, (1983) Voice of Documentary. Film Quarterly.

[3] Fairclough. N, (1992) Discourse and Social change. Cambridge: Polity Press.

[4] Gambier, Y (ed.) (1997) "Language Transfer and Audiovisual Communication. A Bibliography".

[5] Turku. 1994. Center for Translation and Interpreting.

[6] Andrew Chesterman, (2000) Memes of Translation. Philadelphia. Benjamins.

\section{AUTHOR}

M.A with translation studies and now in PhD course at Pusan National University, South Korea

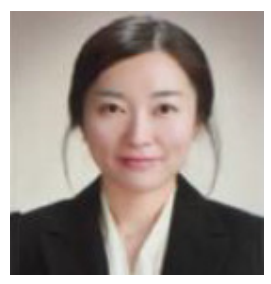




\title{
MACHINE TRANSLATION EVALUATION IN SNS IN TERMS OF USER-CENTERED ORIENTATION
}

\author{
Kim Euna \\ Department of English Language \& Literature, Busan, South Korea
}

\begin{abstract}
This Study explores the role of machine translation by creating a corpus of text from the one of SNS, Facebook, and analyzing and evaluating the corpus data in terms of User-Centered Translation (UCT). For the data to examine, Reuter's Facebook account with language pair of English and Korean was selected due to the fact that the posts are open to the public and use a formal structure of sentences. Based on the corpus, a questionnaire was made to actually see the response from users who are following the Reuter's account and using translation function.
\end{abstract}

\section{KEYWORDS}

Machine Translation, Social Network Services, Corpus, User-Cantered Translation, Target Reader

\section{INTRODUCTION}

Machine Translation (MT) has been applied to many potential areas such as translation of web page or translation of Social Network Services (Wang, 2007). The research about MT has been widely studied but it is still considered to have limits in terms of translation quality (Wilks, 2009). However, the output of MT has shown nearly zero errors compared to human translation since it has been improved from phrase-based, statistical based to the neural based algorithm. The success of MT has brought the promising communication tool in SNS where users around the world share their stories in their own various languages.

In view of the fact that machine translation errors are nearly ignorable, then the users of translation should be taken into account to evaluate the result of MT. But whether it is statistical or neural data, information on translation users are not included or translation process does not have revision process to consider users' information. Therefore, the objectives of this research is to design a corpus with the posts uploaded in Facebook, evaluate and analyse the translation quality along with the translation users' information to see whether the result of translation corresponds to the purpose of users and to help users adapt to the function of MT so that they can gain better communication efficiency. 


\section{BACKGROUND}

\subsection{Development of Machine Translation}

A number of translation systems is developed and the well-known translation includes rule-based machine translation (RBMT), statistical machine translation (SMT), example-based machine translation (EBMT), knowledge-based machine translation (KBMT), hybrid machine translation (Shi, 2013) and recently neural machine translation (NMT). Lastly, Facebook announced that they already have adopted NMT for their translation function.

\subsection{Neural Machine Translation System}

The main issue on the MT was the time delay of the translation process and translation quality. A number of methods have been proposed to solve this problem and the introduction of neuralnetwork-based MT systems showed a great improvement in simultaneous translation and accuracy of standard (Gu et al. 2017). The NMT was proposed by (Kalchbrenner \& Blunsom, 2013), (Stuskever et al., 2014) and (Cho et al., 2014a). The basic idea of NMT is to encode a different length of sentences into a fixed length vector that would summarize the whole sentence, then, decode this encoded vector in the target language to achieve the translation of source sentence (Verma, 2017).

\section{DATA USED}

\subsection{Corpus}

For the data to examine, the posts of the Reuter's Facebook account with language pair of English and Korean were selected due to following reasons; 1) public account, therefore, open to any users 2) official account using a formal structure of sentences for the post. Then, a bilingual corpus of 4000 posts was created and evaluated for the quality of the translation.Each post has a picture with one short English explanation with a length of a sentence, hash tags, which are the feature of the SNS, date, and the writer's name of the post.

\subsection{Translation users}

There are more than 1.2 million followers of the Reuter's account and among them are the translation users whose mother tongue is not English. To distribute questionnaires to Korean users who follow the Reuter's account, the number of users is not enough to observe the result and to lead to the general fact. Therefore, 20 people were randomly chosen and asked them to follow the Reuter's account, use the translation function for the Reuter's posts according to their purposes and distributed the questionnaires.

\section{DISCUSSION}

\subsection{Data evaluation}

The corpus data was first evaluated to analyse the quality of translation by three different researchers and they identified the reasons of decreasing the quality of translation. Various types of automatic evaluation metrics have been developed such as BLEU (BiLingual Evaluation Understudy), WER (Word Error Rate), PER (Position-independent word Error Rate), and TER (Translation Error Rate) (Mohamed, 2012). But those metrics require references to calculate the 
translation quality, three parameters were chosen as a criteria in this research to evaluate the quality of translation; 1) understandability, 2) grammaticality, 3) lexical correctness The understandability means the amount of information that readers are able to understand, the grammaticality means to find out the gramatically ill-formed sentences and the lexical correctness means to identify the untranslated words and suitability of chosen words in the given context (Bohan et al. 2000). Then, 3-point value scale was given to each sentence such as bad, neither bad nor good, and good and computed the average across subject area.

\subsubsection{Evaluation result}

With the language pair of English and Korea, 4000 sentences or posts were evaluated and their average score of translation was calculated. For the understandability, 2465 sentences were rated as good, 1321 as neither bad nor good, 214 as bad. For the grammaticality 2189 sentences were rated as good, 1008 as neither bad nor good, 803 as bad. For the lexical correctness, 2532 sentences were rated as good, 1503 as neither bad nor good, 145 as bad. Every sentence was evaluated by three persons to reduce subjectivity.

\subsection{Questionnaire to translation users}

The questionnaire was distributed to the translation users after they followed the Reuter's account and used the translation function. The questions include 1) users information (age, occupation, fluency of English) 2) purpose of using English Reuter's account (Education, Information gathering, translation, using as secondary source, etc.) 3) evaluation of translation quality in 3 scales with 12 examples 4) phenomena causing the bad translation quality (with open-ended question) 5) satisfaction level of translation function in Facebook in accordance with their purposes.

\subsubsection{Discussion}

The sample group of 20 people was distributed with the questionnaire of 17 questions, which are 16 closed-ended questions and one open-ended question. The result of the questionnaire is shown in Table 1, Figure 1 and Figure 2.

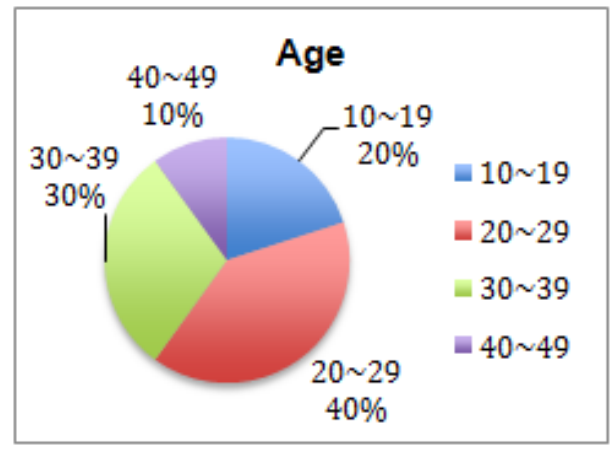

Figure 1. Age of sample group

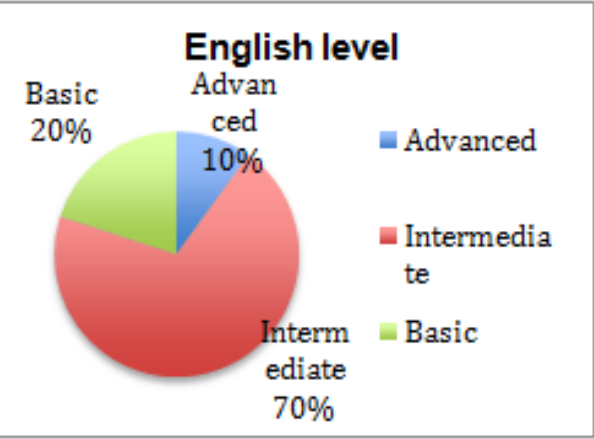

Figure 2. English level of sample group 
Table 1. Result of the questionnaire

\begin{tabular}{|c|c|c|}
\hline \multirow{5}{*}{ Age } & $10-19$ & 4 \\
\hline & $20-29$ & 8 \\
\hline & $30-39$ & 6 \\
\hline & $40-49$ & 2 \\
\hline & Total & 20 people \\
\hline Occupation & \multicolumn{2}{|c|}{$\begin{array}{l}\text { Student, professors, engineer, government } \\
\text { officer, no job, etc. }\end{array}$} \\
\hline & Advanced & 2 \\
\hline & Intermediate & 14 \\
\hline & Basic & 4 \\
\hline & Total & 20 people \\
\hline \multirow{4}{*}{$\begin{array}{l}\text { Evaluation of translation quality } \\
\text { (12 sentences) }\end{array}$} & Good & 3 \\
\hline & Neither bad nor good & 10 \\
\hline & $\mathrm{Bad}$ & 7 \\
\hline & Total & 12 sentences \\
\hline $\begin{array}{l}\text { Phenomena causing the bad } \\
\text { translation quality }\end{array}$ & \multicolumn{2}{|c|}{$\begin{array}{l}\text { Unsuitable lexical choice, idioms, } \\
\text { unknown word, untranslated word, relative } \\
\text { clauses, completeness of sentences, word } \\
\text { order, adverbs, etc. }\end{array}$} \\
\hline \multirow{6}{*}{ Satisfaction level } & Extremely satisfied & 2 \\
\hline & Satisfied & 1 \\
\hline & $\begin{array}{l}\text { Neither satisfied nor } \\
\text { dissatisfied }\end{array}$ & 6 \\
\hline & Dissatisfied & 11 \\
\hline & Extremely dissatisfied & 0 \\
\hline & Total & 20 people \\
\hline
\end{tabular}

People who participated in this research ranged from 10 to 49 years old and their occupation varies such as a student, professor, engineer, government officer or no job at all. Their English level, which was rated by themselves showed that two people were in advanced, 14 were in intermediate and four were in the basic level. Among 12 sentences chosen for the questions, each four sentence was chosen by the research according to the average scale of their translation quality, which was rated by three researchers. Three over 12 sentences were rated as good, 10 as neither bad nor good, and 7 as bad. For the open-ended question, 20 people answered that the phenomena causing the bad translation quality were the unsuitable lexical choice, idioms, unknown word, untranslated word, relative clauses, completeness of sentence, word order, adverbs, etc. Final question result showed that two of 20 people were extremely satisfied with the translation function of the Reuter's posts, one was satisfied, six were neither satisfied nor dissatisfied and 11 were dissatisfied.

\section{CONCLUSIONS}

Although the development of the TM has proven its perfect translation result, the application of the TM in Facebook showed some significant errors that affected the satisfaction level of users. This is because the algorithm of the TM has been developed but the translation process or the memory data does not include the users' information, which means the final result does not correspond to the users' purpose and does not reach to the level satisfying the users. Therefore, they still require the revision process performed by professional translator or users themselves to guarantee the translation quality. This research aims to evaluate the translation quality of the MT applied to the Facebook, but also to help users to adapt to the MT function so that they can achieve their purposes of using SNS and to get the better quality of translated texts. In future research, a retranslation of each sentence by human will be carried out and will be used as a 
reference, therefore, evaluation system such as BLEU, WER, PER, and TER could be used to get a more objective score of the translation quality.

\section{ACKNOWLEDGEMENTS}

The author would like to convey thanks to Prof.Yoon Hwayoung, her supervisor who always gives valuable suggestions and guidance for completion of her research.

\section{REFERENCES}

[1] Wilk, Yorick (2009) Machine Translation, Its Scope and Limits, Springer.

[2] Wang, HaiFeng(2007) "Pivot Language Approach for Phrase-Based Statistical Machine Translation", Machine Translation, Vol. 21, No. 3, pp165-181.

[3] Shi, Chun Qi (2013) "User-Centered Design of Translation Systems", Doctor Thesis Series of Ishida \& Matsubara Laboratory, Kyoto University.

[4] Gu,Jiatao, Neubig, Graham, Cho, Kyung Hyun\& Li, Victor O.K. (2017) "Learning to Translate in Real-Time with Neural Machine Translation", Proceedings of the 15th Conference of the European Chapter of the Association for Computational Linguistics, Vol. 1, pp1053-1062.

[5] Verma, Ajay Anand \& Pushpak, Bhattacharyya (2017) "Literature Survey: Neural Machine Translation", Conference proceedings.

[6] Mohamed, Amine Cheragui (2012) "Theoretical Overview of Machine Translation", Proceedings ICWIT 2012, pp160-169.

[7] Bohan, Niamh, Breidt, Elisabeth \& Volk, Martin (2000) "Evaluating Translation Quality as Input to Product Development",Proceedings of LREC 2000.

\section{AUTHORS}

Kim Euna is currently a representative PhD candidate in Pusan National University in Korea

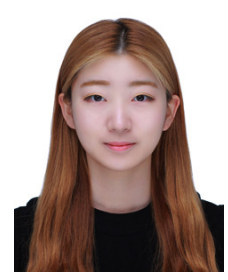




\title{
ARCHITECTURE AND TECHNICAL DEBT AGILE PLANNING METHODOLOGY FOR SOFTWARE PRODUCTION
}

\author{
Aya Elgebeely and Amr Kamel \\ Department of Computer Science, Cairo University, Giza, Egypt.
}

\begin{abstract}
This paper shows an empirical study for a new agile release planning methodology. The case study includes the application of the methodology by two teams in different software business domains (Game development and medical software development). The suggested methodology showed clear improvements in teams' productivity, enhanced software quality and better handling of the overall software architecture and technical debt. It allowed software teams to have more predictable release plan with fewer technical uncertainties. Results are showed in comparison with the traditional scrum release planning approach.
\end{abstract}

\section{KEYWORDS}

Agile, Technical Debt, Release Planning, Software Architecture, Software Engineering

\section{INTRODUCTION}

Accumulated technical debt and technical uncertainty are some of the most common complains of software teams. Business features always tend to get priority over the technical ones that have no clear direct business value. The absence of adequate technical planning tools is one of the factors contributing to this problem [1]. Technical debt according to Martin Fowler [2] happens because of some bad and quick design decisions that were made during the release of software. This debt incurs more development efforts in future to fix the bad code and smells injected in the code base. SEI [3] describes how architectural technical debt should be handled in this short paragraph: "A delicate balance is needed between the desire to release new software features rapidly to satisfy users and the desire to practice sound software engineering that reduces rework. The notion of technical debt creates a concrete way for software development teams to discuss the value and priority of system quality, maintainability, evolvability, and time-to market issues."

The method presented in this paper promises an enhancement in managing technical debt and uncertainties in software planning and implementation. However, it doesn't totally eliminate it, as there will always be unexpected changes throughout the course of the development cycle. The suggested release planning methodology can be considered as an extension to the well known Scrum release planning process. The traditional Scrum release planning focuses on clearly defining business features that should go into a specific version of software. All stakeholders meet together to define the requirements details, business priority and give a relative size using story points or any other estimation technique to each user story. However, discussing the technical implementation details early were always a missing dimension in the release planning meeting [4]. It was found through this empirical study that using only the 'risk' factor to consider uncertainties while planning a software release is insufficient. The large number of 
interdependencies between issues included in a specific software release is one of the major challenges in large-scale software development, which involves large number of contributors as well [5]. Previous studies [6] had shown that a balance is needed between adding new business value and eliminating technical debt to maintain stable software and reduce the increasing risk of technical debt accumulation.

Therefore, this method helps development teams to explore technical debt, architectural changes, and research and development efforts lying on the critical path of delivering the required business value. The suggested method helps development teams to visualize all the technical dependencies (through a dependency matrix) so that an implementation strategy is manifested to follow through sprints. The suggested release planning methodology considers both business priorities and the technical dimension as well. It also helps the development team to justify the time be spent in laying down technical infrastructure (that may not have direct business value) for other future releases to come.

\section{RELATED WORK}

Eltjo Poort introduced the iterative approach of addressing architectural changes and technical debt through his talk "Architecture Roadmapping" [7]. Wolfang Trumler and Frances Paulisch [8] coupled unit and integration tests with the low level details of requirements' specification to avoid technical debt and enhance release predictability. Nelson Sekitoleko [9] found that improved knowledge sharing between technical and managerial staff on different levels can significantly improve the ability to create a good plan that considers interdependencies between features and addresses both business and technical challenges. Robert Phaal and Gerrit Muller [10] discussed the value of having what they called "Linked analysis grids" that is used in directly linking business requirements with technological aspects of these requirements, then use a scoring technique that ranks product's backlog according to technical priority and complexity. Wojciech and Dorota [11] investigated the inherent risks in different agile methodologies, and concluded that a special risk mitigation process is mandatory. They found that these risks won't be addressed by merely following agile best practices. This proves that additional investigation and analysis are required on all phases of the software development process for teams adopting agile methodology. Marjan [12] presented mathematical formalization of flexible release planning, using integer linear programming models and methods. They believe that using this ILP method in release planning will help in selecting the most appropriate features backlog based on revenues and costs, which takes into consideration both the business and technical perspectives. Jason Ho and Guenther Ruhe [13] introduced a method called Goal-Questions-Metrics (GQM) which helps in quantifying the technical debt coupled with a specific release in order to be able to give more accurate release dates.

\section{RESEARCH METHODOLOGY}

The methodology presented in this paper was applied via empirical experiments involved two development teams from different domains, but all of them were following the Scrum methodology. The goal was to include the real technical complexity in deciding on the features of a given product release. And the other goal was to reduce the technical uncertainties and waste elimination from the software development process.

One of the main activities that are done in a typical Scrum release planning meeting is the story points' estimates of the user stories which is named as (sizing). The estimation is done by the technical team, with the presence of the product owner and Srcum Master. The technical team discusses the implementation details, risks and complexity. Story points have many usages during scrum iterations 'sprints' and future releases as well. Story points help the team know the relative 
size and development efforts needed for a user story against each other. It helps the team select their stories wisely and put a realistic time estimate for this story accordingly. It also helps in measuring and maintaining team's velocity over releases and iterations.

However, the technical teams' ability to analyze and predict the technical complexities of user stories and relative risks is affected by many factors. Some factors to mention are the teams' experience level and seniority, domain knowledge, project size and complexity, the business volatility and the novelty of development tools and frameworks.

In many occurrences, teams' judgment in the beginning of the project drastically changes afterwards, which yields to inaccurate story points sizing and time estimates during the later sprints. One of the major advantages of the new methodology presented in this paper, that it contributes in enhancing the design of the product and enables the team to address architecture concerns, technical debt and other dependencies continuously and early in the process. It also helps in envisioning the business impact and importance of such architectural changes to all stakeholders.

As shown in the related work, most of the methodologies revolved around going to the lower level of technical details and do more through technical analysis in the planning process. And they found that just following the basic release planning technique is not enough to mitigate the technical risks and in correctly judging the release backlog from the business side due to their unawareness with inherent implementation complexities and risks.

The suggested methodology is similar to the traditional release planning by beginning with the product owner and stakeholders explaining the new features of prospect products. Yet, a series of technical analysis meetings are done before the sizing event takes place. These technical analysis meetings should be correctly facilitated by the scrum master or the facilitator the team chooses, to avoid falling into analysis paralysis trap, ensure reliable outcome and that everyone in the team has contributed.

\subsection{Release Planning Stage 1 (Pair Analysis)}

The technical analysis starts after the business perspective (new set of requirements) being shared with the team. Then the team is allowed a time box (1-2 days) to think solely or in pairs about the features suggested by the business side. Inside this time box every single team member is allowed the opportunity to reflect, search and write down all her technical concerns and questions.

\subsection{Release Planning Stage 2 (Swarm Analysis)}

The next step is that the whole team is gathered again in an assembly point, where the scrum master explains the meeting process and expected outcomes. Then the team is re-distributed into sub teams (3-5 members) each. Sub teams should be as diverse as possible. For instance, a senior developer, a junior developer, a tester and architect will form a perfect sub team. Each sub team should have the business backlog with them, and they would exchange together the concerns and questions they had collected in stage 1. Each sub team should compile a list of technical considerations and thoughts they agreed upon about each feature in the backlog. The time allowed for sub teams discussions varies from ( 1 to 3 hours) according to the size of the backlog and sub teams. However, it's suggested that sub teams' size do not exceed 5 team members to reduce conflicts and communication channels opened within the sub teams' discussion. Sub teams should nominate a representative who will talk on behalf of them when teams are gathered again in analysis stage 3 . 
A typical scrum team will have about 3 to 6 sub teams. In this stage, the facilitation role of Scrum Master is mostly needed. She should be rotating over sub teams to make sure they are all progressing with their discussions, not blocked by minor conflicts, or over analyzing a feature. She should also make sure that every team member is actively sharing in the discussion, and no one is taking a passive attitude. Also, she will be the time keeper for sub teams, by reminding them of how much time is remaining for them to maintain their momentum.

\subsection{Release Planning Stage 3 (Analysis Consolidation)}

In this stage, all the technical teams are gathered again to share their collected concerns about the new backlog. The team goes through the backlog, and for each user story, every team representative shares the sub-team's concern about it if they had any. The concerns and thoughts being shared are categorized into one of five categories, (New feature request - technical debt Architectural change - Risk - R\&D "Research and Development"). A board is created for each category and issues are written on sticky notes with different color representing the five areas. This helps the team keep track of issues being shared without repetition and help them maintain the big picture physically.

\subsection{Release Planning Stage 4 (Technical Analysis Matrix)}

In discussing the value of the Technical analysis, we will use a quotation from Stojanovic \& Dahanayake [14] "By its definition a component hides a complexity of its interior so that components can help in easier making an architecture metaphor and architecture prototypes (spikes) as the main design-level artifacts. Components as a mechanism for organizing business requirements in cohesive business service providers, and at the same time a blueprint of future implementation, can provide bi-directional traceability between business needs and software artifacts. That certainly helps in better understanding and communication across the project, and more straightforward iterations and increments. Good business-driven, component-oriented architecture design can reduce the need for refactoring (that can be also time -consuming task), as well as permanent customer presence, in the case it is not feasible."

\subsubsection{Example of Technical Analysis Matrix}

This is a sample view of the technical analysis matrix and the dependencies domains included inside it with sample data.

Table 1. Example of technical analysis matrix.

\begin{tabular}{|c|c|c|c|c|c|c|c|}
\hline Feature & $\begin{array}{c}\text { Dependent } \\
\text { Features }\end{array}$ & $\begin{array}{c}\text { Confidence } \\
\text { Level }\end{array}$ & $\begin{array}{l}\text { Risk } \\
(1-5)\end{array}$ & $\begin{array}{c}\text { Bugs } \\
\text { ID }\end{array}$ & $\begin{array}{c}\text { Pending } \\
\text { UI/UX }\end{array}$ & $\begin{array}{c}\text { Technical } \\
\text { Debt }\end{array}$ & $\begin{array}{c}\text { Architecture } \\
\text { Change }\end{array}$ \\
\hline $\mathrm{A}$ & $(\mathrm{B}, \mathrm{E})$ & Medium & 3 & 546 & $\begin{array}{l}\text { Progress } \\
\text { bar }\end{array}$ & $\begin{array}{l}\text { Thread-Safe } \\
\text { implementation }\end{array}$ & $\begin{array}{l}\text { Threading } \\
\text { module, Job } \\
\text { Queues }\end{array}$ \\
\hline B & & High & 3 & & & & \\
\hline $\mathrm{C}$ & (A) & Medium & 2 & 342 & $\begin{array}{l}\text { New } \\
\text { CSS, log } \\
\text { In page }\end{array}$ & $\begin{array}{l}\text { Refactoring of } \\
\text { Login pages }\end{array}$ & $\begin{array}{l}\text { Security } \\
\text { Module }\end{array}$ \\
\hline $\mathrm{D}$ & & Low & 4 & $\begin{array}{l}321, \\
542\end{array}$ & & & \\
\hline$E$ & & High & 1 & & & & \\
\hline
\end{tabular}




\subsection{Release Planning Stage 5 (Technical Intuition)}

At this stage, each new business feature is linked with its related decencies in the dependency matrix. The team discusses the related dependencies and accordingly set the confidence level of implementing this feature. The confidence level is a qualitative metric (High - Medium - Low); It depicts the overall confidence of the team of implementing that feature, after the dependencies and details of the features had been discussed [15].

Although it's a qualitative metric, yet different pervious experiences mentioned that this qualitative approach of simply asking the team their confidence level was much better approach than only looking to the reports and resource allocation to determine the confidence level.

\subsection{Release Planning Stage 6 (Requirements Sorting)}

After all the technical details and dependencies have been discussed the team meets again with the business side to share the relative risks and complexities associated with the release suggested features. Hence, the business side and product owner have a chance to reprioritize the release backlog after they got technical insights. This is very suitable for projects with high technical complexity or niche technologies. At this stage the team is capable of sorting the backlog with respect to business priority and technical complexity as well. Spikes, technical debt, architecture can now added early in the sprints as the team as well as non-technical partners knows the business impact of these technical tasks.

\section{RESULTS DISCUSSION}

An empirical experiment was made with two teams in different domains, first team composed of 12 developer and 2 testers. The development team has 3 of them dedicated to work on R\&D tasks, while the others shared in the overall development process. The suggested methodology helped in reducing the overall release duration by 4 times less than the time used to deliver similar release backlog with the traditional release planning approach. It also allowed the team to address critical architecture concerns that allowed them to enhance different areas in the design including testability, logging, modularization and optimization. The number of production bugs reported decreased from an average of 10 bugs reported after the software release to 2 bugs per release after production given a release backlog of relatively similar complexity.

Table 2. Data comparison for the first team.

\begin{tabular}{|l|l|l|}
\hline Factors & $\begin{array}{l}\text { Release 12 with traditional } \\
\text { release planning }\end{array}$ & $\begin{array}{l}\text { Release 13 with technical } \\
\text { perspective workshop }\end{array}$ \\
\hline Developers & 13 & 11 \\
\hline Average years of experience & 2.5 yrs & 1.5 yrs \\
\hline $\begin{array}{l}\text { Release Backlog size } \\
\text { features/story points) }\end{array}$ & 230 story point & 210 story point \\
\hline Changes during release & Massive & Minimal \\
\hline User stories & Shallow & Detailed \\
\hline Testing team & 3 & 2 \\
\hline Release time challenges & 4 months after due date & 3 weeks after due date \\
\hline $\begin{array}{l}\text { No. of Blocker and critical bugs } \\
\text { after release }\end{array}$ & 17 & 4 \\
\hline
\end{tabular}

The second team composed of 4 developers, 1 tester and 1 designer. The time to release the release under test was enhanced by 6 times faster than the traditional working scheme they used. The team tended to tackle the technical debt in an ad-hoc manner, once they started a new feature 
that includes a technical debt, they work on it regardless its risk, cost or added value. There were a lot of cross dependencies between team members that caused idle time for the designer, tester or other developers. By following the suggested approach, dependencies were clear from the release start date, the team was focused; tasks were distributed in a lean way that minimized cross dependencies between team members. And it drastically reduced the delay caused by having any of the team members waiting for someone else in order to be able to start progressing in a given task.

Table 3. Data comparison for the second team.

\begin{tabular}{|l|l|l|}
\hline Factors & $\begin{array}{l}\text { Version 1 with traditional } \\
\text { release planning }\end{array}$ & $\begin{array}{l}\text { Version with technical } \\
\text { perspective workshop }\end{array}$ \\
\hline Developers & 5 & 4 \\
\hline Average years of experience & 2 yrs & 3 yrs \\
\hline $\begin{array}{l}\text { Release Backlog size } \\
\text { (features/story points) }\end{array}$ & 100 story point & 120 story point \\
\hline Changes during release & Massive & Minimal \\
\hline User stories & Detailed & Detailed \\
\hline Testing team & 0 & 1 \\
\hline Release time challenges & 2 months & No challenges \\
\hline $\begin{array}{l}\text { No. of Blocker and critical bugs } \\
\text { after release }\end{array}$ & $\begin{array}{l}21 \text { and a failed client site } \\
\text { deployment }\end{array}$ & 7 and a smooth deployment \\
\hline
\end{tabular}

\section{CONCLUSION}

This paper presented a methodology that increases the confidence of estimates and works on eliminating many wastes presented inside a software development process of a given team. These enhancements are basically linked with the inclusion of a deep technical analysis with the release planning process. The application of the methodology was described and the role of every stakeholder during the release planning event was discussed. Performance indicators measured during the development and after production showed substantial enhancement in team's performance and software quality.

The key for reducing technical uncertainty is doing enough upfront analysis prior starting a software release. Technical debt, new architecture changes and software development research can be addressed by following the above-mentioned release planning method that protects the whole development team from taking wrong decisions and underestimation of technical complexities.

\section{REFERENCES}

[1] H. C. Benestad and J. E. Hannay, "Does the prioritization technique affect stakeholders' selection of essential software product features?," Proceedings of the ACM-IEEE international symposium on Empirical software engineering and measurement, pp. 261-270, 2012.

[2] M. Fowler, “Technical Debt,” October 2003. [Online]. Available: https://martinfowler.com/bliki/TechnicalDebt.html.

[3] “Architectural Technical Debt," [Online]. Available: http://www.sei.cmu.edu/architecture/research/arch_tech_debt/.

[4] K. Schwaber, "SCRUM Development Process," in Business Object Design and Implementation , London, 1997. 
[5] C. R. B. de Souza, D. Redmiles and G. Mark, "Management of interdependencies in collaborative software development," in 2003 International Symposium on Empirical Software Engineering, 2003. ISESE 2003. Proceedings., Rome, Italy, 2003.

[6] K. Power, "Understanding the impact of technical debt on the capacity and velocity of teams and organizations: Viewing team and organization capacity as a portfolio of real options," in 4th International Workshop on Managing Technical Debt (MTD), San Francisco, CA, USA, 2013.

[7] E. R. Poort, “Agile Architecture Roadmapping," in SATURN 2016, San Diego, CA USA, 2016.

[8] W. Trumler and F. Paulisch, "How "Specification by Example" and Test-Driven Development Help to Avoid Technial Debt," in IEEE 8th International Workshop on Managing Technical Debt (MTD), Raleigh, NC, USA , 2016.

[9] N. Sekitoleko, F. Evbota, E. Knauss, A. Sandberg, M. Chaudron and H. H. Olsson, "Technical Dependency Challenges in Large-Scale Agile Software Development," in International Conference on Agile Software Development, Rome, Italy, 2014.

[10] R. Phaal and G. Muller, "An architectural framework for roadmapping: Towards visual strategy," Technological Forecasting and Social Change, pp. 39-49, 2009.

[11] W. Walczak and D. Kuchta, "Risks characteristic to Agile project management methodologies and responses to them," Operations Research and Decisions, pp. 75-95, 2013.

[12] M. d. Akker, S. Brinkkemper, G. Diepen and J. Versendaal, "Software product release planning through optimization and what-if analysis," Information and Software Technology, pp. 101-111, 2008.

[13] J. Ho and G. Ruhe, "When-to-release decisions in consideration of technical debt," in Managing Technical Debt (MTD), 6th International Workshop, Victoria, BC, Canada, 2014.

[14] Z. Stojanovic, A. Dahanayake and H. G. Sol, "Modeling and Architectural Design in Agile Development Methodologies," in Evaluation and Modeling Methods for Systems Analysis and Development, Velden, Austria, 2003.

[15] P. A. Beavers, "Managing a Large Agile Software Engineering Organization," in Agile Conference, Washington, DC, USA, 2007.

[16] P. A. Beavers, "Managing a Large "Agile" Software Engineering Organization," IEEE Computer Society, 2007.

\section{AUTHORS}

Aya $\mathbf{R}$ Elgebeely is a masters student in computer science department in Cairo University, who has over 9 years experience in software development and leading development teams. She worked in IBM Egypt for 5 years and currently working as a technical consultant with many tech startups in Egypt as software delivery manager to boost software team's performance.

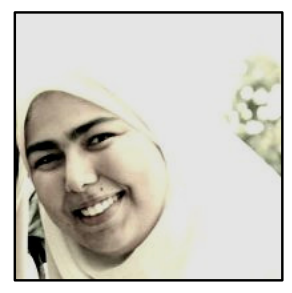




\section{AUTHOR INDEX}

Yunsil Jo 01

Kim Euna 09

Aya Elgebeely 15

Amr Kamel 15 